
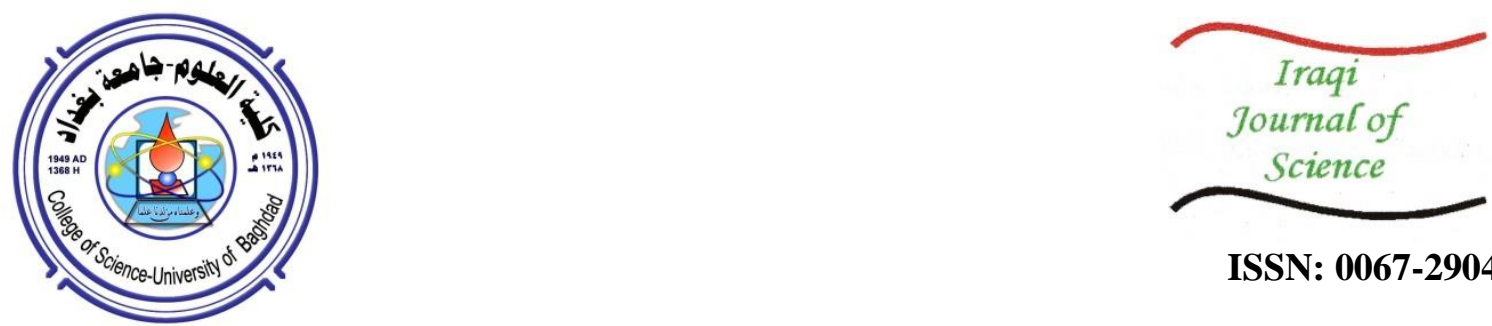

ISSN: 0067-2904

\title{
Serum Level of Interleukin-33, C-Reactive Protein, and Troponin in Iraqi Coronary Artery Disease Patients
}

\author{
Athraa Z. Al-Obaidi*, Jinan M. J. Al-Saffar \\ Department of Biotechnology, College of Science, University of Baghdad, Baghdad, Iraq
}

Received: 28/7/ 2019

Accepted: 28/ 8/2019

\begin{abstract}
Coronary artery disease (CAD) is a condition of an inadequate supply of oxygenated blood to a portion of the myocardium. It typically occurs when there is an imbalance between supply and demand of myocardial oxygen. The most common cause of myocardial ischemia is atherosclerotic disease of an epicardial coronary artery or arteries which is sufficient to cause a regional reduction in myocardial blood flow and inadequate perfusion of the myocardium supplied by the involved coronary artery. Fifty CAD subjects ( 23 females and 27 males) were enrolled in this study in addition to thirty healthy control subjects (13 female and 17 male). This study aimed to measure the serum levels of interleukin IL- 33, C- reactive protein and troponin in $\mathrm{CAD}$ and their association with lipid profile by using enzyme-linked immune sorbent assay (ELISA). $\mathrm{T}$ results showed that high-density lipoprotein (HDL) was statistically high while differences in cholesterol, triglyceride and lowdensity lipoprotein (LDL) were statistically non-significant between CAD patients and controls. Moreover, the serum level of IL-33 and CRP were statistically higher in patients than controls, while troponin levels were not significantly different. In addition, the present study demonstrates that IL-33, CRP, and Troponin were not associated with lipid profile. The relationship of IL-33 with CRP and troponin was non-significant.
\end{abstract}

Keywords: Coronary artery disease, Interleukin-33, C-reactive protein, Troponin, High-density lipoprotein, Low-density lipoprotein, Cholesterol, Triglyceride.
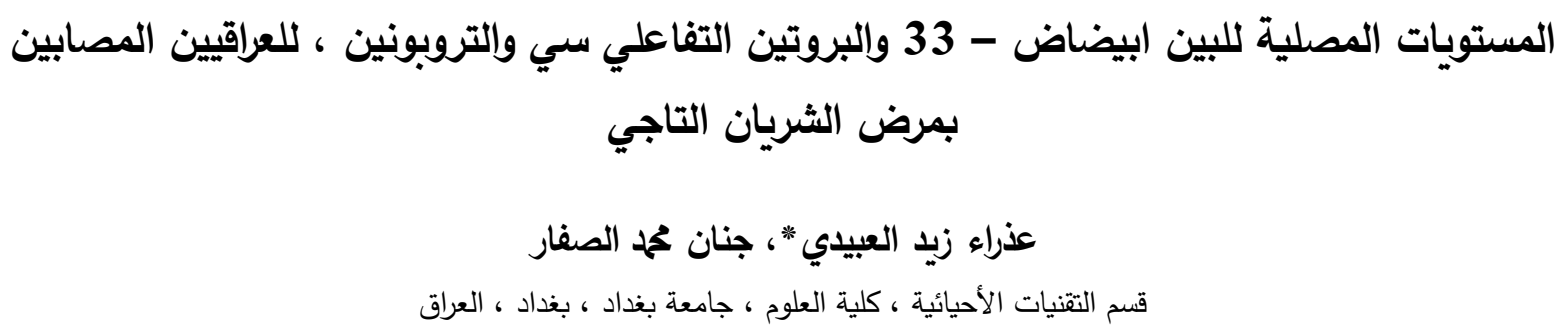


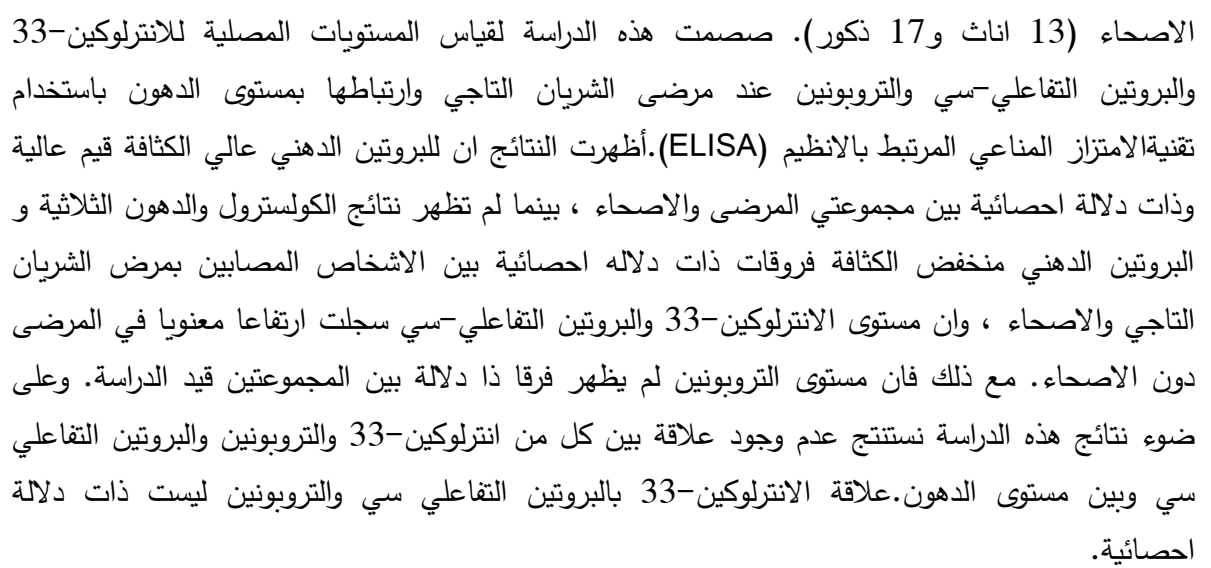

\section{Introduction}

Coronary artery disease (CAD) means narrowing of the coronary arteries (arteries that supply blood to the heart). This narrowing is due to a bulid up in the walls of the arteries of plaque (deposits made up of cholesterol, other fats, and calcium) - a process called atherosclerosis (hardening of the arteries). If a plaque becomes delicate and breaks, a blood clot will quickly form that can block blood flow in the artery and may lead to myocardial infarction (death of the heart muscle area supplied by the blocked artery), often referred to as a heart attack [1]. Coronary heart disease was initially thought to be a disease of modern humans, with the cause being attributed to contemporary lifestyles [2]. Patients are considered stable if they are asymptomatic or if their symptoms are controlled by medications or revascularization $[3,4]$.

Interleukin-33 is a recently discovered cytokine that belongs to the IL-1 superfamily and is mainly expressed by different types of structural cells [5, 6]. IL-33 binds to a specific receptor named T1/ST2 (also known as ST2) that belongs to the toll-like receptor (TLR)/IL1R superfamily [7]. Interleukin-33 transcript and protein is widely expressed in different cell types including in cells of both hematopoietic as well as non-hematopoietic origins such as macrophages, dendritic cells, fibroblasts, adipocytes, smooth muscle cells, endothelial cells, bronchial, osteoblast and intestinal epithelial cells [8,9]. IL-33 is a cytokine that is constitutively expressed in the nuclei of endothelial and epithelial cells $[10,11]$. The full-length of IL-33, pro-IL-33, serves as a gene regulator that is localized in the nuclei [12], whereas mature IL-33 serves as a cytokine after release into the extracellular space at the onset of tissue injury $[13,14]$. C-reactive protein (CRP) is an acute-phase protein that serves as an early marker of inflammation or infection. The protein is synthesized in the liver and is normally found at concentrations of less than $10 \mathrm{mg} / \mathrm{L}$ in the blood. During infectious or inflammatory disease states, CRP levels rise rapidly within the first 6 to 8 hours and peak at levels of up to $350-400 \mathrm{mg} / \mathrm{L}$ after 48 hours [15]. CRP binds to phosphocholine expressed on the surface of damaged cells, as well as to polysaccharides and peptosaccharides present on bacteria, parasites, and fungi. This binding activates the classical complement cascade of the immune system and modulates the activity of phagocytic cells, supporting the role of CRP in the opsonization (i.e. the process by which a pathogen is marked for ingestion and destruction by a phagocyte) of infectious agents and dead or dying cells [16]. When the inflammation or tissue destruction is resolved, CRP levels fall, making it a useful marker for monitoring disease activity [17]. Cardiac troponin biomarkers are an essential component used to diagnose acute MI [18]. In the late 1980s, cTnI was proposed as marker of cardiac cell death, and is now widely used and established as the guideline-recommended marker in order to assist in the diagnosis of myocardial injury in clinical pathologies, such as post-surgery myocardium trauma, chemotherapy cardiotoxicity and many other diseases related to cardiac muscle injury [19].

This study aims to measure serum levels of IL-33, CRP and troponin in CAD patients.

\section{Materials and methods}

\section{Sample collection}

The samples were composed of fifty CAD patients (27 male and 23 female) aged between 3 months and 70 years and thirty genetically unrelated, healthy volunteers (17 men and 13 women) aged between 22 and 46 years. The blood samples collection extended through the period of October 2018 to February 2019. Blood samples of patients were collected from Ibn Al-Bitar Specialized Center for Cardiac Surgery, Baghdad- Iraq. All patients gave their informed written approval to participate in the 
study. The diagnosis was confirmed by experienced doctors. The entire participants were of unrelated Iraqi origin and had similar geographic data.

\section{Blood sample collection}

Blood samples were collected from CAD patients and healthy controls by using a $10 \mathrm{ml}$ disposable syringe in gel-containing tubes, left to clot at room temperature $\left(20-25{ }^{\circ} \mathrm{C}\right)$ for 10 minutes, then centrifuged at $5000 \mathrm{rpm}$ for 5 minutes to obtain serum. Serum was separated after centrifugation and divided into three Eppendorf tubes to avoid multiple freezing and thawing and kept frozen for further experiments.

\section{Laboratory methods}

Serum levels of IL-33, CRP and troponin was determined by using enzyme-linked immunosorbent assay (ELISA). The lipid profile was analyzed according to the results of laboratory tests ordered during outpatient visits, which included cholesterol levels, triglycerides, HDL and LDL [20].

\section{Statistical analysis}

Analysis of data was carried out by using the available statistical package of SPSS-25 (Statistical Packages for Social Sciences- version 25). Data were presented in simple measures of frequency, percentage, mean, standard deviation, and range (minimum-maximum values). The significance of the differences of different means (quantitative data) was tested by using Students t-test for the differences between two independent means, while Pearson correlation was calculated for the correlation between two quantitative variables with its t-test for testing the significance of correlation. The correlation coefficient value (r) was either positive (direct correlation) or negative (inverse correlation) with a value of $<0.3$ representing no correlation, $0.3-<0.5$ represent weak correlation, $0.5-<0.7$ moderate strength, $>0.7$ strong correlation. In addition to correlation, the $\mathrm{r} 2$ was calculated (The coefficient of determination), i.e. when the value of $r=0.58$, then $r 2=0.34$, this means that $34 \%$ of the variation in the values of $y$ may be accounted for by knowing values of $\mathrm{x}$ or vice versa [21].

\section{Result and Discussion}

\section{Lipid profile}

The concentrations of lipid profile compounds of eighty individuals (50 CAD patients and 30 controls) are presented in Table-1. The mean concentration of cholesterol in CAD patients compared to controls was $157.92 \pm 45.28$ versus $165.37 \pm 30.35 \mathrm{mg} / \mathrm{dl}$, respectively, while for triglyceride was $127.22 \pm 72.87$ versus $96.50 \pm 70.59 \mathrm{mg} / \mathrm{dl}$, for $\mathrm{LDL}$ was $91.50 \pm 40.87$ versus $93.37 \pm 22.59 \mathrm{mg} / \mathrm{dl}$. The differences were not significant $(\mathrm{P}>0.05)$. While, the HDL mean concentration was $40.58 \pm 12.52$ versus $52.70 \pm 15.28 \mathrm{mg} / \mathrm{dl}$ and this difference was statistically significant $(\mathrm{P}<0.05)$.

Table 1- Lipid profile of CAD patients and healthy control

\begin{tabular}{|c|c|c|c|}
\hline \multicolumn{1}{|c|}{ Parameters } & $\begin{array}{c}\text { CAD Patients } \\
(\mathbf{n = 5 0})\end{array}$ & $\begin{array}{c}\text { Controls } \\
(\mathbf{n = 3 0})\end{array}$ & Probability \\
\hline Cholesterol(mg/dl) & $157.92 \pm 45.28$ & $165.37 \pm 30.35$ & 0.427 \\
\hline Triglyceride(mg/dl) & $127.22 \pm 72.87$ & $96.50 \pm 70.59$ & 0.069 \\
\hline HDL(mg/dl) & $40.58 \pm 12.52$ & $52.70 \pm 15.28$ & $0.0001^{*}$ \\
\hline LDL(mg/dl) & $91.50 \pm 40.87$ & $93.37 \pm 22.59$ & 0.819 \\
\hline
\end{tabular}

\section{Serum level of IL-33}

The serum level of IL-33 was significantly higher $(\mathrm{P}=0.004)$ in patients experiencing $\mathrm{CAD}$ as compared to controls ( $115.33 \pm 116.20$ versus $59.72 \pm 52.53 \mathrm{pg} / \mathrm{ml}$ respectively), as shown in Table- 2 .

Table 2-IL-33 level of CAD patients compared to controls

\begin{tabular}{|c|c|c|c|}
\hline Groups & No. & $\begin{array}{c}\text { IL-33concentration } \\
\text { pg/ml(Mean } \pm \text { S.D) }\end{array}$ & Probability \\
\hline CAD & 50 & $115.33 \pm 116.20$ & $0.004^{*}$ \\
\hline Control & 30 & $59.72 \pm 52.53$ & \\
\hline
\end{tabular}

*Significant difference $\mathrm{P}<0.05$ 


\section{The association of IL-33 with lipid profile}

The results of the correlation of IL-33 with cholesterol, triglyceride, HDL, and LDL in the patients and the control group are illustrated in Table-3. The results showed that the correlation coefficient $r$ of cholesterol was higher in CAD patients than in the controls $(0.053$ versus $-0.070, p=0.715$ versus 0.712 ), while the $\mathrm{r}$-value of triglyceride was -0.002 versus $-0.112, \mathrm{p}=0.989$ versus 0.557 . In addition, the $r$ value of HDL was -0.105 versus $0.052, p=0.469$ versus 0.783 and that for LDL was 0.103 versus $-0.060, p=0.475$ versus 0.752 . The differences were not statistically significant $(\mathrm{p}>0.05$ and $\mathrm{r}<0.3)$.

Table 3-Correlation of IL-33 with Lipid profile

\begin{tabular}{|c|c|c|c|}
\hline \multirow{2}{*}{ Lipid profile } & \multicolumn{3}{|c|}{ IL-33(pg/ml) } \\
& $\begin{array}{c}\text { Correlation coefficient } \\
\text { and probability }\end{array}$ & Patients & Controls \\
\hline \multirow{2}{*}{ Cholesterol(mg/dl) } & $\mathbf{r}$ & 0.053 & -0.070 \\
\hline \multirow{2}{*}{ Triglyceride(mg/dl) } & $\mathbf{p}$ & 0.715 & 0.712 \\
\hline HDL(mg/dl) & $\mathbf{r}$ & -0.002 & -0.112 \\
\hline LDL(mg/dl) & $\mathbf{p}$ & 0.989 & 0.557 \\
\hline & $\mathbf{r}$ & -0.105 & 0.052 \\
\hline & $\mathbf{p}$ & 0.469 & 0.783 \\
\hline
\end{tabular}

\section{Serum level of CRP}

Table-4 shows the mean distribution of CRP in CAD patients compared to healthy controls. The results showed an increased level of CRP in CAD patients compared to control $(0.07 \pm 0.04$ versus $0.03 \pm 0.03 \mathrm{mg} / \mathrm{ml}$, respectively), while the difference was statistically significant $(\mathrm{P}=0.0001)$.

Table 4-CRP level of CAD patients compared to controls.

\begin{tabular}{|c|c|c|c|}
\hline Groups & No. & $\begin{array}{l}\text { CRP concentration } \\
\text { mg/ml(Mean } \pm \text { S.D) }\end{array}$ & Probability \\
\hline CAD & 50 & $0.07 \pm 0.04$ & \multirow{2}{*}{$0.0001 *$} \\
\hline Controls & 30 & $0.03 \pm 0.03$ & \\
\hline
\end{tabular}

*Significant difference $\mathrm{P}<0.05$

\section{The association of CRP with lipid profile}

The correlation relationship of CRP with cholesterol, triglyceride, HDL, and LDL in patients and control groups is illustrated in Table-5. The results showed that the correlation coefficient values of cholesterol in CAD patients versus controls were $(-0.170$ versus $-0.185, p=0.239$ versus 0.328 , for triglyceride was -0.330 versus $-0.178, \mathrm{p}=0.019$ versus 0.345 . In addition, the $\mathrm{r}$ value for HDL was 0.151 versus $-0.102, \mathrm{p}=0.295$ versus 0.592 and for $\mathrm{LDL}$ was -0.031 versus $-0.068, \mathrm{p}=0.830$ versus 0.722 . The results were not statistically significant $(p>0.05$ and $R<0.3)$

Table 5-Correlation of CRP with lipid profile

\begin{tabular}{|c|c|c|c|}
\hline \multirow{2}{*}{ Lipid profile } & \multicolumn{3}{|c|}{ CRP(mg/ml) } \\
& $\begin{array}{c}\text { Corrlation coefficient } \\
\text { and probability }\end{array}$ & Patients & Controls \\
\hline \multirow{2}{*}{ Cholesterol(mg/dl) } & $\mathbf{r}$ & -0.170 & -0.185 \\
\hline \multirow{2}{*}{ Triglyceride(mg/dl) } & $\mathbf{p}$ & 0.239 & 0.328 \\
\hline \multirow{2}{*}{ HDL(mg/dl) } & $\mathbf{r}$ & $-0.330^{*}$ & -0.178 \\
\hline \multirow{2}{*}{ LDL(mg/dl) } & $\mathbf{p}$ & 0.019 & 0.345 \\
\hline & $\mathbf{r}$ & -0.151 & -0.102 \\
\hline & $\mathbf{p}$ & 0.295 & 0.592 \\
\hline & $\mathbf{p}$ & -0.031 & -0.068 \\
\hline
\end{tabular}




\section{Serum level of troponin}

Table- 6 shows the mean distribution of troponin in CAD patients compared to healthy controls. The results did not show relative changes in the level of troponin in CAD patients compared to the control $(6.83 \pm 1.88$ versus $6.30 \pm 0.50 \mathrm{mg} / \mathrm{ml})$, where the difference was not statistically significant $(\mathrm{P}=$ $0.136)$.

Table 6-Troponin level of CAD patients and controls

\begin{tabular}{|c|c|c|c|}
\hline Groups & No. & $\begin{array}{c}\text { Troponin concentration mg/ml } \\
(\text { Mean } \pm \text { S.D) }\end{array}$ & Probability \\
\hline CAD & 50 & $6.83 \pm 1.88$ & 0.136 NS \\
\hline Controls & 30 & $6.30 \pm 0.50$ & 0.50 \\
\hline
\end{tabular}

$\mathbf{N S}=$ non significant $\mathrm{P}>0.05$

\section{The association of Troponin with lipid profile}

The correlation relationship of troponin with cholesterol, triglyceride, HDL, and LDL in patient and control groups is illustrated in Table-7. The results showed that the correlation coefficient of cholesterol in CAD patients to controls was -0.109 versus $-0.114, p=0.453$ versus 0.547 , while for triglyceride was $(-0.204$ versus $-0.203, p=0.155$ versus 0.282 . In addition, the $r$ value for HDL was 0.041 versus $0.021, \mathrm{p}=0.778$ versus 0.914 and for $\mathrm{LDL}-0.032$ versus $-0.041, \mathrm{p}=0.827$ versus 0.830 . The results were not statistically significant $(\mathrm{p}>0.05$ and $\mathrm{r}<0.3)$.

Table 7-Correlation of Troponin with lipid profile

\begin{tabular}{|c|c|c|c|}
\hline \multirow{2}{*}{ Lipid profile } & \multicolumn{3}{|c|}{ Troponin $(\mathbf{n g} / \mathbf{m l})$} \\
& $\begin{array}{c}\text { Correlation coefficient } \\
\text { and probability }\end{array}$ & Patients & Controls \\
\hline \multirow{2}{*}{ Cholesterol(mg/dl) } & $\mathbf{r}$ & -0.109 & -0.114 \\
\hline \multirow{2}{*}{ Triglyceride(mg/dl) } & $\mathbf{p}$ & 0.453 & 0.547 \\
\hline \multirow{2}{*}{ HDL(mg/dl) } & $\mathbf{r}$ & -0.204 & -0.203 \\
\hline LDL(mg/dl) & $\mathbf{p}$ & 0.155 & 0.282 \\
\hline & $\mathbf{p}$ & -0.041 & 0.021 \\
\hline & $\mathbf{p}$ & 0.778 & 0.914 \\
\hline & $\mathbf{p}$ & -0.032 & -0.041 \\
\hline
\end{tabular}

\section{The association of IL-33 with CRP and Troponin}

The correlation of IL-33 with CRP and Troponin between patient and control group is illustrated in Table-8. The results showed that the correlation coefficient $r$ of CRPl was higher in CAD patients than in the controls $(0.228$ versus $0.071 \mathrm{p}=0.112$ versus 0.710$)$, whereas the $\mathrm{r}$-value of troponin was -0.048 versus $-0.118, \mathrm{p}=0.743$ versus 0.923 . The results were not statistically significant $(\mathrm{p}>0.05$ and $\mathrm{r}<$ $0.3)$

Table 8-Correlation of IL-33 with CRP and troponin.

\begin{tabular}{|c|c|c|c|}
\hline \multirow{2}{*}{} & \multicolumn{3}{|c|}{ IL-33(pg/ml) } \\
\hline \multirow{2}{*}{ CRP } & $\begin{array}{c}\text { Correlation coefficient } \\
\text { and probability }\end{array}$ & Patients & Controls \\
\hline \multirow{2}{*}{ Troponin } & $\mathbf{r}$ & 0.228 & 0.071 \\
\hline & $\mathbf{p}$ & 0.112 & 0.710 \\
\hline & $\mathbf{r}$ & -0.048 & 0.018 \\
\hline
\end{tabular}

\section{Discussion}

In the current study, we investigated the concentrations of IL-33, CRP, troponin and lipid profile components in eighty individuals of Iraqi people, including fifty CAD patients and thirty apparently healthy volunteers. We investigated the association between IL-33, CRP, and troponin with lipid profile as well as the relationships among IL-33, CRP, and Troponin. 
The results showed a high level of IL-33 in CAD patients. Nuclear IL-33 is released from necrotic human coronary artery's smooth muscle cells, human adult cardiac myocytes and cardiac fibroblasts in vitro and, therefore, cell damage induces the release of IL-33 [22]. Also, a high serum concentration of IL-33 was observed in IHD [23]. In the present study, CRP concentration was also higher in CAD patients than the healthy controls. CRP is considered as an excellent biomarker of inflammation, while it is non-specific for certain diseases including the risk of MI, stroke, peripheral arterial disease, and sudden cardiac death [24]. A recent study reported that there is a strong association between serum CRP levels and coronary artery disease risk [25]. Troponin can be released into the bloodstream as a result of myocardial injury. Troponin plays a vital role in the diagnosis of Non-ST Segment Elevation Myocardial Infarctions (NSTEMIs). It is imperative to keep in mind the multiple non-ischemic and non-cardiac causes and potential factors that may lead to elevations of troponin levels [26]. High levels of hsTnI are associated with the underlying burden of coronary atherosclerosis, more rapid progression of CAD, a higher risk of all-cause mortality, and incident cardiovascular events [27]. Troponin concentration in CAD patients in the present study was within the normal range, and this disagrees with the previously reported association with increased CVD risk, which may be due small sample size or medications intake [28]. The lipid profile analysis showed only a significant association between HDL and CAD There is a clear inverse relationship between serum high-density lipoproteincholesterol (HDL-C) concentrations and the risk for coronary heart disease (CHD), even at lowdensity lipoprotein-cholesterol (LDL-C) levels below $70 \mathrm{mg} / \mathrm{dL}$ [29]. High HDL-C, reduced HDL phospholipid content, and cholesterol efflux capacity are associated with the paradoxical development of CAD [30]. Moreover, there was no significant association between IL-33, CRP, or troponin with lipid profile in CAD patients and controls. This is the first study that investigates the association of IL-33, CRP, and troponin together with lipid profile in CAD. A non-significant association was found between adipose tissue IL-33 and circulating lipids (total cholesterol, LDL, HDL, and TG) in glycemia disease [31]. Another study showed a highly significant elevation in lipid profile in a diabetic postmenopausal group [32]. CRP was also shown to be raised with the increase of TG, with the possibility to use it as a marker to predict the future risk of CAD [33]. Another study reported that there was no association between CPR and lipid parameters [34], while a non-significant association was reported between CRP level and dyslipidemia [35]. In addition, in subjects with chest pain, total cholesterol, triacylglycerol, and low-density lipoproteins levels were higher in the subjects with a positive troponin than those with a negative troponin [36]. In addition, subjects who develop chest pain due to a cardiac event, confirmed by positive troponin test, had significantly greater levels of TC.TG, LDL when compared to those levels in subjects without cardiac events, as indicated by negative troponin test [37]. To our knowledge, this is the first study that found a negative correlation between IL-33, CRP and Troponin. Interestingly the investigated relationship between serum levels of these molecules indicated non-significant differences, which is in disagreement with Abbas [38] who found that IL-33 is positively correlated with CRP in Celiac disease (CD) in Iraqi women. However, there were no literatures found investigating the relationship between IL-33 and Troponin.

\section{Conclusion}

In summary, it was found that IL-33 and CRP were statistically associated with CAD, while troponin levels showed no statistically significant differences as compared to the control group. Moreover, testing the lipid profile showed a significant increase in HDL level, whereas no significant differences were obtained among cholesterol, triglycerides and LDL levels between CAD patients and controls. Moreoverno correlation was found between IL-33, CRP or troponin with lipid profile. In addition, there was no correlation between IL-33, CRP and troponin. Taking into consideration the limitations of the present study, represented by the small sample size, further studies are recommended with a higher sample size.

\section{Acknowledgments}

This work was supported by Ibn Al-Bitar Specialized Center for Cardiac Surgery, Baghdad, Iraq, and we appreciate the support of the University of Baghdad, Collage of Sciences and the Biotechnology Department. In addition, we appreciate the contribution of ASCO learning center.

\section{References}

1. Zeituni, A. E., Carrion, J. and W. Cutler, C. 2010. Porphyromonas gingivalis-dendritic cell interactions: consequences for coronary artery disease. Journal of oral microbiology, 2(1): 5782. 
2. Hajar, R. 2017. Coronary heart disease: From mummies to 21st century. Heart views: the official journal of the Gulf Heart Association, 18(2): 68.

3. Fihn, S. D., Gardin, J. M., Abrams, J., Berra, K., Blankenship, J. C., Dallas, A. P. and King, S. B. 2012. ACCF/AHA/ACP/AATS/PCNA/SCAI/STS guideline for the diagnosis and management of patients with stable ischemic heart disease: a report of the American College of Cardiology Foundation/American Heart Association task force on practice guidelines, and the American College of Physicians, American Association for Thoracic Surgery, Preventive Cardiovascular Nurses Association, Society for Cardiovascular Angiography and Interventions, and Society of Thoracic Surgeons. Journal of the American College of Cardiology, 60(24): e44-e164.

4. Montalescot, G., Sechtem, U., Achenbach, S., Andreotti, F., Arden, C. and Budaj, A. 2013. The Task Force on the management of stable coronary artery disease of the European Society of Cardiology. Eur Heart J, 34: 2949-3003.

5. Yasuoka, S., Kawanokuchi, J., Parajuli, B., Jin, S., Doi, Y., Noda, M. and Suzumura, A. 2011. Production and functions of IL-33 in the central nervous system. Brain research, 1385: 8-17.

6. Liew, F. Y., Pitman, N. I. and McInnes, I. B. 2010. Disease-associated functions of IL-33: the new kid in the IL-1 family. Nature Reviews Immunology, 10(2): 103.

7. Miller, A. M. 2011. Role of IL-33 in inflammation and disease. Journal of inflammation, 8(1): 22.

8. Pichery, M., Mirey, E., Mercier, P., Lefrancais, E., Dujardin, A., Ortega, N. and Girard, J. P. 2012. Endogenous IL-33 is highly expressed in mouse epithelial barrier tissues, lymphoid organs, brain, embryos, and inflamed tissues: in situ analysis using a novel Il-33-LacZ gene trap reporter strain. The Journal of Immunology, 188(7): 3488-3495.

9. Schmitz, J., Owyang, A., Oldham, E., Song, Y., Murphy, E., McClanahan, T. K. and Gorman, D. M. 2005. IL-33, an interleukin-1-like cytokine that signals via the IL-1 receptor-related protein ST2 and induces T helper type 2-associated cytokines. Immunity, 23(5): 479-490.

10. Baekkevold, E. S., Roussigné, M., Yamanaka, T., Johansen, F. E., Jahnsen, F. L., Amalric, F. and Girard, J. P. 2003. Molecular characterization of NF-HEV, a nuclear factor preferentially expressed in human high endothelial venules. The American journal of pathology, 163(1): 69-79..

11. Pichery, M., Mirey, E., Mercier, P., Lefrancais, E., Dujardin, A., Ortega, N. and Girard, J. P. 2012. Endogenous IL-33 is highly expressed in mouse epithelial barrier tissues, lymphoid organs, brain, embryos, and inflamed tissues: in situ analysis using a novel Il-33-LacZ gene trap reporter strain. The Journal of Immunology, 188(7): 3488-3495.

12. Choi, Y. S., Park, J. A., Kim, J., Rho, S. S., Park, H., Kim, Y. M. and Kwon, Y. G. 2012. Nuclear IL-33 is a transcriptional regulator of NF- $\mathrm{kB}$ p65 and induces endothelial cell activation. Biochemical and biophysical research communications, 421(2): 305-311.

13. Liew, F. Y., Pitman, N. I. and McInnes, I. B. 2010. Disease-associated functions of IL-33: the new kid in the IL-1 family. Nature Reviews Immunology, 10(2): 103.

14. Lunderius Andersson, C., Enoksson, M., \& Nilsson, G. 2012. Mast cells respond to cell injury through the recognition of IL-33. Frontiers in immunology, 3: 82.

15. Ramamoorthy, R. D., Nallasamy, V., Raghavendra Reddy, N. E. and Maruthappan, Y. 2012. A review of C-reactive protein: A diagnostic indicator in periodontal medicine. Journal of pharmacy \& bioallied sciences, 4(Suppl 2): S422.

16. Shaldoum, F. M., Hassan, M. I. and Hassan, M. S. 2018. Natural Honey Bee venom Manipulates Human Immune Response. Egyptian Journal of Hospital Medicine, 72(4):.

17. Kanaparthy, A., Kanaparthy, R. and Niranjan, N. 2012. Evaluation of serum C-reactive protein levels in subjects with aggressive and chronic periodontitis and comparison with healthy controls. Dental research journal, 9(3): 261.

18. Daubert, M. A. and Jeremias, A. 2010. The utility of troponin measurement to detect myocardial infarction:review of the current findings. Vascular health and risk management, 6: 691.

19. Garg, P., Morris, P., Fazlanie, A. L., Vijayan, S., Dancso, B., Dastidar, A. G., Plein, S., Mueller, C. and Haaf, P. 2017. Cardiac biomarkers of acute coronary syndrome: from history to highsensitivity cardiac troponin. Internal and emergency medicine, 12(2): 147-155.

20. da Cunha, M. G., Batista, A. L. F., Macedo, M. S., Machado Filho, C. D. A. S. and Fonseca, F. L. A. 2015. Study of lipid profile in adult women with acne. Clinical, cosmetic and investigational dermatology, 8: 449. 
21. Daniel, W. W., \& Cross, C. L. 2018. Biostatistics: a foundation for analysis in the health sciences. Wiley.

22. Demyanets, S., Kaun, C., Pentz, R., Krychtiuk, K. A., Rauscher, S., Pfaffenberger, S., \& Huber, K. 2013. Components of the interleukin-33/ST2 system are differentially expressed and regulated in human cardiac cells and in cells of the cardiac vasculature. Journal of molecular and cellular cardiology, 60: 16-26.

23. Jafarinia, M., Firuzsalari, F. G. and Zaringol, M. 2018. Serum levels of interleukin (IL)-33 in patients with ischemic heart disease. MOJ Immunol, 6(2): 29-32.

24. Shrivastava, A. K., Singh, H. V., Raizada, A. and Singh, S. K. 2015. C-reactive protein, inflammation and coronary heart disease. The Egyptian Heart Journal, 67(2): 89-97.

25. Onitilo, A. A., Engel, J. M., Stankowski, R. V., Liang, H., Berg, R. L. and Doi, S. A. 2012. Highsensitivity C-reactive protein (hs-CRP) as a biomarker for trastuzumab-induced cardiotoxicity in HER2-positive early-stage breast cancer: a pilot study. Breast cancer research and treatment, 134(1): 291-298.

26. Arshed, S., Luo, H. X., Zafar, S., Regeti, K., Malik, N., Alam, M. and Yousif, A. 2015. Elevated troponin I in the absence of coronary artery disease: A case report with review of literature. Journal of clinical medicine research, 7(10): 820.

27. Samman Tahhan, A., Sandesara, P., Hayek, S. S., Hammadah, M., Alkhoder, A., Kelli, H. M. and Gafeer, M. M. 2018. High-Sensitivity Troponin I Levels and Coronary Artery Disease Severity, Progression, and Long-Term Outcomes. Journal of the American Heart Association, 7(5): e007914.

28. Willeit, P., Welsh, P., Evans, J. D., Tschiderer, L., Boachie, C., Jukema, J. W. and Mooijaart, S. P. 2017. High-sensitivity cardiac troponin concentration and risk of first-ever cardiovascular outcomes in 154,052 participants. Journal of the American college of cardiology, 70(5): 558-568.

29. Kosmas, C. E., Martinez, I., Sourlas, A., Bouza, K. V., Campos, F. N., Torres, V. and Guzman, E. 2018. Hig h-density lipoprotein (HDL) functionality and its relevance to atherosclerotic cardiovascular disease. Drugs in context, 7.

30. Agarwala, A. P., Rodrigues, A., Risman, M., McCoy, M., Trindade, K., Qu, L. and Rader, D. J. 2015. High-density lipoprotein (HDL) phospholipid content and cholesterol efflux capacity are reduced in patients with very high HDL cholesterol and coronary disease. Arteriosclerosis, thrombosis, and vascular biology, 35(6): 1515-1519.

31. Hasan, A., Kochumon, S., Al-Ozairi, E., Tuomilehto, J. and Ahmad, R. 2019. Association between Adipose Tissue Interleukin-33 and Immunometabolic Markers in Individuals with Varying Degrees of Glycemia. Disease markers, 2019.

32. Hassan, A. J. 2015. Study The Relationship of IL-33 with Adiponectin in Postmenopausal Female with and without Type 2 Diabetes Mellitus. Medical Journal of Babylon, 12(3): 618-624.

33. Firdous, S. 2014. Correlation of CRP, fasting serum triglycerides and obesity as cardiovascular risk factors. J Coll Physicians Surg Pak, 24(5): 308-313.

34. Li, J. J., Jiang, H., Huang, C. X., Fang, C. H., Tang, Q. Z., Xia, H. and Li, G. S. 2002. Elevated level of plasma C-reactive protein in patients with unstable angina: its relations with coronary stenosis and lipid profile. Angiology, 53(3): 265-272.

35. Gupta, S., Gupta, V. K., Gupta, R., Arora, S. and Gupta, V. 2013. Relationship of high-sensitive C-reactive protein with cardiovascular risk factors, clinical presentation and angiographic profile in patients with acute coronary syndrome: An Indian perspective. Indian heart journal, 65(3): 359.

36. Kumar, A. and Sathian, B. 2013. Correlation between lipid profile and troponin I test results in patients with chest pain in Nepal. Asian Pacific journal of tropical biomedicine, 3(6): 487-491.

37. Dali, B. 2014. Clinical Profile, Dyslipidemia and ACS-a Correlation. Journal of the Nepal Medical Association, 52(195):.

38. Abass, E. A. 2017. Relationship Between Interleukin-33 (IL-33) and C-Reactive Protein in Iraqi Women Patients with Celiac Disease. Ibn AL-Haitham Journal For Pure and Applied Science, 27(1): 288-296. 